\title{
AS METODOLOGIAS ATIVAS COMO INSTRUMENTO PARA SE ATINGIR UMA APRENDIZAGEM SIGNIFICATIVA, REFLEXIVA E INTERDISCIPLINAR NO ENSINO JURÍDICO
}

Aline Fonseca Franco, José de Oliveira Costa Filho

Universidade do Oeste Paulista - UNOESTE, Direito Presidente Prudente, SP. E-mail: alinefonsecafranco@yahoo.com.br

\section{RESUMO}

Diante de um cenário globalizado que exige do profissional do Direito a capacidade de enfrentar questões sociais complexas e diante do contingente de informação de fácil acesso aos estudantes, verificou-se necessário o estudo visando à análise da metodologia mais adequada ao processo de ensino aprendizagem, em consonância às diretrizes curriculares do curso de graduação em Direito. Verificou-se que muitos estudiosos defendem que a concepção bancária da Educação, na qual o estudante seria mero receptor do conhecimento, se configura como opressora e inibidora da formação crítica e reflexiva do estudante. De outro lado, as metodologias ativas são defendidas como métodos eficazes para participação ativa dos estudantes, capazes de permitir aprendizagem significativa, pensamento crítico e reflexivo. Concluiu-se que as metodologias ativas, por meio da problematização, são importantes no desenvolvimento das funções mentais dos estudantes de Direito, na formação crítica, reflexiva e interdisciplinar, bem como para geração da corresponsabilidade no processo ensino aprendizagem.

Palavras-chave: Metodologias ativas; ensino-aprendizagem, pensamento crítico-reflexivo; interdisciplinaridade; Direito.

\section{ACTIVE METHODOLOGIES AS AN INSTRUMENT TO ACHIEVE A MEANINGFUL LEARNING, REFLECTIVE AND INTERDISCIPLINARY IN JURIDICAL EDUCATION}

\begin{abstract}
Faced with a global scenario that requires the right professional capacity to deal with complex social issues and on the information contingent easily accessible to students, it was found necessary to study aimed at analyzing the most appropriate methodology to the teaching and learning process, according to the curriculum guidelines of the degree course in law. It was found that many scholars argue that the banking concept of education, in which the student would be mere knowledge receiver is configured as oppressive and inhibiting the critical and reflective training student. On the other hand, active methods are defended as effective methods for active participation of students, able to allow meaningful learning, critical thinking and reflective. It was concluded that the active methodologies, through questioning, are important in the development of mental functions of law students, critical, reflective and interdisciplinary training as well as for generation of co-responsibility in the learning process.
\end{abstract}

Keywords: active methodologies; teaching and learning, critical and reflective thought; interdisciplinarity; interdisciplinarity; Law. 


\section{INTRODUÇÃO}

A nova era digital e a grande oferta de conhecimento disponível nos meios digitais advindas de um mundo moderno e globalizado têm impulsionado mudanças no campo da Pedagogia do ensino. Nesse cenário, o papel do educador no processo de ensino-aprendizagem e, mais precisamente no ensino jurídico onde se preponderou por muito tempo a utilização de aulas expositivas como método de transmissão de conhecimentos, precisa ser adequado às demandas de uma geração fruto da modernidade e preparado para enfrentamento da realidade em sua grande complexidade.

Diante desse turbilhão de informações disponíveis e do perfil da geração dos estudantes, impõe-se uma nova configuração do processo de ensino que deverá se voltar para o desenvolvimento de uma postura crítica e reflexiva dos alunos, proporcionando um ambiente dialético e dinâmico.

Assim, o presente estudo visa fazer uma reflexão sobre a utilização de novas metodologias no ensino jurídico frente às exigências de formação do estudante mais próxima da realidade social. Pretende-se ainda refletir sobre o papel do educador nesse processo e sua importante contribuição para provocação de uma participação ativa dos estudantes no processo ensino-aprendizagem.

\section{METODOLOGIA}

O presente trabalho utilizou o método dialético dedutivo e o levantamento bibliográfico.

\section{RESULTADOS}

Há muito já se tem pensado sobre a arte de ensinar e desde o século XVII, em seu livro Didática Magna, Comenius, "Pai da Didática" e precursor da Pedagogia Moderna, preconizando o aprendizado contínuo, por toda a vida, e o desenvolvimento do pensamento lógico, em substituição à simples memorização. O Filósofo propôs à época uma educação universal, com acesso a todas as pessoas, defendendo que a educação é a forma de humanizar o homem, de fazê-lo passar de um estado bruto para o de ser humano propriamente, caracterizado pela capacidade de aprender a pensar por si:

Que todos se formem com uma instrução não aparente, mas verdadeira, não superficial, mas sólida; ou seja, que o homem, enquanto animal racional, se habitue a deixar-se guiar, não pela razão dos outros, mas pela sua, e não apenas a ler nos livros e a entender, ou ainda a reter e a recitar de cor as opiniões dos outros, mas a penetrar por si mesmo até o âmago das próprias coisas e a tirar delas os conhecimentos genuínos e utilidade (COMENIUS, 2001, p.154)

Essa concepção de aprendizado crítico-reflexivo e pautado na autonomia foi ganhando adeptos, vindo a ser amplamente defendida por Paulo Freire (1993), preconizador de um Pedagogia Libertadora e que propõe uma educação crítica a serviço da transformação social, uma Pedagogia humanista, problematizadora; de questionamento, pergunta, indignação, tolerância, autonomia, defendendo que "a educação que liberta é aquela que faz com que o aluno desenvolva consciência crítica e participe ativamente no processo de aprendizagem, pois só assim o homem torna-se, efetivamente livre".

Como relata Borges e Alencar (2014) em sua obra, existia-se uma visão de que para ser um bom processor universitário, bastaria ter um vasto conhecimento na área da disciplina lecionada associada a uma boa oratória, entendimento este que atualmente estaria sendo refutado a cada dia, quando se denota que os estudantes do nível superior na atualidade chegam com suas personalidades formadas, possuidores de uma bagagem de conhecimento grande decorrentes de 
uma sociedade globalizada. Defendem também o autores a necessidade de desenvolvimento de habilidades didáticas suficientemente eficazes para se buscar uma educação compatível com a realidade atual, ressaltando a relevância da mediação do professor nos processos de elaboração do conhecimento.

Faria (2013) também ressaltou em seu estudo a importância das mudanças na prática pedagógica de ensino jurídico e da necessidade da realização das mudanças curriculares na graduação de Direito na Fundação Getúlio Vargas para se adaptar às novas necessidades de formação de um profissional com autonomia intelectual e com capacidade para a construção de novos institutos jurídicos face às demandas presentes na sociedade atual, destacando, fundamentalmente, quanto à superação de uma concepção de direito excessivamente formalista, que se articulava com uma prática pedagógica marcada pelo olhar dogmático, pela busca do domínio enciclopédico e pela inexistência de diálogo efetivo entre o direito e outras áreas do conhecimento. Enfatizou a autora que as mudanças curriculares e inovações didáticas partiram do reconhecimento da real necessidade de assumir um ensino jurídico que adotasse como referências obrigatórias para a construção do raciocínio jurídico, da centralidade dos problemas sociais, das controvérsias e conflitos de interesses individuais ou coletivos.

Esta linha coaduna com o disposto na Diretrizes Básicas das Educação que preconiza o estímulo de práticas de estudo independente e uma progressiva autonomia do estudante.

Nesse sentido, Mossini (2010) citando Melo Filho (1997), defende que o desenvolvimento do pensamento reflexivo constitui-se na maior preocupação metodológica do ensino jurídico, o qual deve ser capaz de estimular o raciocínio e a criatividade, bem como exercitar uma visão crítica para formar cidadãos conscientes de seu papel na sociedade, estando aptos para entender o contexto onde vão operar e o sentido de sua ação no mundo.

Outro ponto a destacar é a necessidade de formação interdisciplinar, humanística e axiológica do estudante, conforme o disposto na Resolução no 9, de 29 de setembro de 2004, editada pela Câmara de Educação Superior do Conselho Nacional de Educação/MEC, a qual instituiu as diretrizes curriculares nacionais dos cursos de graduação em Direito, impondo que o curso deve integrar o estudante na sociedade, estabelecendo as relações do Direito com outras áreas do saber, abrangendo, dentre outros, estudos que envolvam conteúdos essenciais sobre Antropologia, Ciência Política, Economia, Ética, Filosofia, História, Psicologia e Sociologia, evitando-se o puro tecnicismo jurídico para construir um ensino, democrático, pluralista e interdisciplinar.

\section{O PAPEL DO PROFESSOR E DO ESTUDANTE NA CONSTRUÇÃO DO CONHECIMENTO SIGNIFICATIVO}

Para se conseguir alcançar a formação do estudante desejada pelas diretrizes nacionais e condizentes às necessidades sociais atuais, há que ser analisado o papel do professor e do estudante no processo de ensino-aprendizagem, bem como as metodologias adequadas na prática pedagógica.

Os métodos tradicionais, segundo Morán (2013), faziam sentido quando o acesso à informação era difícil, mas com o advento da internet e a divulgação aberta de muitos cursos e materiais, a postura do professor deve ser adaptada a essa realidade.

Vê-se, portanto, que a atuação do professor como o único detentor e transmissor do conhecimento está ultrapassada e constitui como manifestação da opressão, segundo Paulo Freire:

Eis aí a concepção bancária da educação, em que a única margem de ação que se oferece aos educandos é a de receberem os depósitos, guardá-los e arquivá-los. Na visão "bancária" da educação, o "saber" é uma doação dos que julgam sábios aos que julgam nada saber. Doação que se funda numa das manifestações instrumentais da ideologia da opressão e absolutização da 
ignorância, que constitui o que chamamos de alienação e ignorância, segundo a qual esta se encontra sempre no outro (FREIRE,1996, p.58).

Freire (1996) defende que a construção de uma sociedade pensante tem por base a ação docente, mas que, para que isso seja possível, o docente precisa assumir seu verdadeiro compromisso e encarar o caminho do aprender a ensinar.

Em consonância a esse entendimento Mossini (2010), afirma que a prática pedagógica conteudista do ensino jurídico, centrada na transmissão de fatos, conceitos e procedimentos deve ser substituída pela formação para o pensamento, para a capacidade de identificar e resolver problemas e para a aquisição de competências e habilidades que possibilitem ao futuro bacharel a conquista da sua autonomia intelectual e seu crescimento para lidar com os muitos e complexos desafios da realidade sempre mutante.

Assim, impõe-se uma nova postura do docente e habilitação para a adoção de novas práticas pedagógicas capazes de superar a hegemonia da aula expositiva fundada numa atitude passiva do aluno no processo de aprendizagem. Nesse sentido, destacamos os ensinamentos de Vygotsky:

“...o professor universitário deve ser um agente mediador deste processo, propondo desafios aos seus acadêmicos e ajudando-os a resolvê-los, ou proporcionando atividades em grupo, em que aqueles que estiverem mais adiantados possam cooperar com os que tiverem mais dificuldades. (VYGOSTKY, 1988, p. 125)

Há, portanto, a necessidade de introdução na prática pedagógica das metodologias ativas, tendo como um dos adeptos dessa prática Paulo Freire (1996), defensor da problematização na construção de novos conhecimentos.

As Metodologias Ativas baseiam-se em formas de desenvolver o processo de aprender, utilizando experiências reais ou simuladas, visando às condições de solucionar, com sucesso, desafios advindos das atividades essenciais da prática social, em diferentes contextos, segundo (BERBEL, 2011).

Borges e Alencar (2014) ensinam que a problematização utilizada pelas metodologias ativas objetiva alcançar e motivar o estudante, colocando-o frente a um problema sobre o qual deverá examinar, refletir, contextualizar e promover a ressignificação conforme suas descobertas. Avaliam que trata de um recurso didático de grande importância, podendo favorecer de forma significativa e eficaz o processo de ensino-aprendizagem.

Na medida em que há uma aproximação com a realidade e com os problemas da sociedade, impondo ao estudante uma postura ativa para buscar o conhecimento necessário à resolução da situação posta em estudo, as metodologias ativas provocam o exercício do senso crítico e reflexivo pelo estudante, permitindo-se, assim, segundo Mossini (2010) analisar as repercussões da problemática e das eventuais soluções a ela atribuídas (ou a ausência de soluções) sobre a vida social.

Morán (2013) defende que é necessária a adoção de metodologias em que os alunos se envolvam em atividades cada vez mais complexas, em que tenham que tomar decisões e avaliar os resultados. Ressalta ainda o autor que quanto mais aprendamos próximos da vida, melhor, sendo as metodologias ativas pontos de partida para avançar para processos mais avançados de reflexão, de integração cognitiva, de generalização, de reelaboração de novas práticas. Acrescenta Malheiros (2012) ainda que, para obtenção de uma aprendizagem significativa, é necessária a aproximação do conhecimento teórico com a prática, uma vez que o conhecimento só se pereniza quando é aplicado. 
Verifica-se, pois, que um ensino efetivo se traduz em uma aprendizagem significativa e esta se concretiza com a solidez dos conhecimentos que foram construídos embasados nos anseios individuais, face aos problemas e realidade sociais.

\section{A NECESSIDADE DE FORMAÇÃO INTERDISCIPLINAR E SUA IMPORTÂNCIA NA APRENDIZAGEM SIGNIFICATIVA}

Muito também tem se analisado a necessidade da formação interdisciplinar do educando, de forma a reduzir a fragmentação do conhecimento para construção de uma interligação entre as várias disciplinas individualizadas nos currículos institucionais.

Morin (1997) ensina que as disciplinas, quando isoladas dentro das especializações, muitas vezes não oferecem respostas aos problemas de nossa sociedade, levando, frequentemente, a uma abordagem unidimensional e separada do contexto que os produz.

As primeiras ações em direção à interdisciplinaridades, segundo Fazenda (2003), surgiram na Europa, na década de 1960, iniciadas por movimentos estudantis que buscavam aproximação do ensino às realidades de sua época em "oposição à alienação da Academia às questões da cotidianidade, às organizações curriculares que evidenciavam a excessiva especialização e a toda e qualquer proposta de conhecimento que incitava o olhar do aluno em uma única, restrita e limitada direção". No Brasil, as discussões sobre interdisciplinaridade se iniciaram no final da década de 60 e, segundo Fazenda (2003).

Para discutir a educação do futuro, realizou-se em 1998 a Conferência Mundial sobre Educação Superior, convocada pela UNESCO, ocasião em que foi criada a Declaração Mundial sobre Educação Superior no Século XXI: Visão e Ação, a qual dispõe que a educação superior deve reforçar seu papel de serviço extensivo à sociedade, especialmente as atividades voltadas para a eliminação da pobreza, intolerância, violência, fome, deterioração do meio ambiente e enfermidades, principalmente com a utilização de uma perspectiva interdisciplinar e transdisciplinar para a análise dos problemas sociais.

Com isso, verifica-se a defesa de uma nova forma de abordagem da educação baseada na integração dos conhecimentos sob uma perspectiva interdisciplinar. Mossini (2010) nas palavras de Georges Gusdorf, filósofo e um dos principais precursores da interdisciplinaridade, cita que "o destino da ciência multipartida seria a falência do conhecimento, pois, na medida em que nos distanciamos de um conhecimento em sua totalidade, estaríamos decretando a falência do humano".

Para que ocorra a efetivação do ensino interdisciplinar, Fazenda (2003) explica que deverá haver a interação professor/aluno e professor/professor, pois a educação só tem sentido no encontro, na "mutualidade", numa relação em que haja reciprocidade, amizade e respeito mútuo.

A interdisciplinaridade exigirá do professor postura diferenciada, conforme cita Fazenda (2003):"O professor interdisciplinar traz em si um gosto especial por conhecer e pesquisar, possui um grau de comprometimento diferenciado para com seus alunos, ousa novas técnicas e procedimentos de ensino. Antes, porém, analisa-os e dosa-os convenientemente". Cita ainda que os cinco princípios que subsidiam a prática interdisciplinar são: humildade, espera, respeito, coerência e desapego.

Nessa linha, Mossini (2010) enfatiza que as práticas pedagógicas em sala aula devem exceder uma visão fragmentada e descontextualizada do ensino, tornando as aprendizagens significativas, devendo o professor de Direito reconhecer o aluno como o centro do processo ensino-aprendizagem e aceitar seu papel de mediador e o sentido de totalidade do ensino. 


\section{CONSIDERAÇÕES FINAIS}

Diante de todo exposto, verifica-se a necessidade de se implantar um ensino mais próximo das necessidades da sociedade e dos padrões impostos pelo mundo moderno, adotando-se uma prática pedagógica e metodologias de ensino que visem à aprendizagem significativa. $O$ ensino jurídico baseado na postura passiva do estudante e na concepção bancária do conhecimento em muito se distancia da formação crítica e reflexiva e da Pedagogia problematizadora defendida por Paulo Freire

Nesse sentido, o papel do professor no processo de ensino-aprendizagem deve se direcionar para uma atuação estimuladora da busca ativa do conhecimento pelos estudantes, promovendo atividades que visem ao desenvolvimento crítico do estudante, de forma a atribuir um significado ao ato de aprender, gerando ainda uma corresponsabilidade e interatividade dialética.

O uso das metodologias ativas no ensino jurídico, as quais estabelecem uma aproximação com a realidade social por meio da problematização, também impõe a utilização das funções mentais dos estudantes de Direito de pensar, raciocinar, observar, refletir, entender, combinar, permitindo-se ainda uma avaliação sobre as soluções e argumentos apresentados pelos estudantes frente às situações reais delineadas, as quais muitas vezes abrange várias áreas do conhecimento.

Com isso, relevo ainda destacarmos a importância da interdisciplinaridade para a formação holística do indivíduo, vez que a atuação na ciência do Direito, na prestação da Justiça e no desenvolvimento da cidadania requer uma formação geral e humanística, não se resumindo à técnica, objetivando-se, outrossim, a integração com outras áreas do saber (Antropologia, Ciência Política, Ética, Filosofia etc.), em consonância às diretrizes curriculares nacionais do curso de graduação em Direito.

\section{REFERÊNCIAS}

BERBEL, N. A. N. As metodologias ativas e a promoção da autonomia de estudantes. Ciências Sociais e Humanas, Londrina, v. 32, n. 1, p. 25-40, jan./jun. 2011 https://doi.org/10.5433/1679$\underline{0383.2011 v 32 n 1 p 25}$

BORGES, T. S; ALENCAR, G. Metodologias ativas na promoção da formação crítica do estudante: o uso das metodologias ativas como recurso didático na formação crítica do estudante de ensino superior. Cairu em Revista. Jul/Ago 2014, Ano 03, nº4, p. 119-143 , ISSN 22377719.

COMENIUS, I. A. Didática Magna. Fundação Calouste Gulbenkian, eBooksBrasil.com. Disponível em: http://www.ebooksbrasil.org/adobeebook/didaticamagna.pdf. Acesso em 11 mar 2016.

FARIA, A.A. A Formação de Novas competências: articulação da grade curricular e de metodologias participativas no curso da Direito GV. IN: SILVEIRA, Vladimir Oliveira da; SANCHES, Samyra Haydêe Dal Farra Naspolini; COUTO, Mônica Bonetti (org.). Educação jurídica. São Paulo: Saraiva, 2013

FAZENDA, I. C. A.. Interdisciplinaridade: História, Teoria e Pesquisa.11. ed. Campinas, SP: Papirus, (1994) 2003.

FREIRE, P. Pedagogia do Oprimido. São Paulo, Editora Paz e Terra, 1996.

MALHEIROS, B.T. Didática Geral. Rio de Janeiro: LTC, 2012. 
MOSSINI, D. E. S. Ensino Jurídico: história, currículo e interdisciplinaridade. Tese para obtenção do título de Doutor em Educação pela PUC São Paulo. São Paulo, 2010. Disponível em: file://C:/Users/Aline/Desktop/EAD/TCC\%20DANIELA\%20ENSINO\%20JURIDICO\%20INTERDISCIPLINAR. $\underline{\mathrm{html}}$ Acesso em 11 mar 2016.

MORÁN, J. Mudando a educação com metodologias ativas. Disponível em:

http://www2.eca.usp.br/moran/wp-content/uploads/2013/12/mudando moran.pdf Acesso em 11 mar 2016.

MORIN, E. Sobre a reforma universitária. In: ALMEIDA, Maria da Conceição de; MOTTA, Elias de Oliveira. Direito educacional e educação no século XXI. Brasília: UNESCO, 1997.

VYGOTSKY, L. Linguagem, desenvolvimento e aprendizagem. São Paulo: Ícone, 1988. p. 125. 